\title{
Policies and Institutions for Grid-Connected Renewable Energy: "Best Practice" vs. the Case of China
}

\author{
Clara García ${ }^{*}$ \\ ${ }^{1}$ Complutense University, Madrid, Spain \\ *Corresponding author. Tel: +34 633504758, E-mail: clara.garcia@ccee.ucm.es
}

\begin{abstract}
A consensus seems to have emerged around what constitutes "best practice" in policymaking and institution-building for the deployment of grid-connected renewable energy (GCRE). However, this consensus, found scattered throughout reports and policy papers, or in the discourse of policymakers and businesspeople, has yet to be systematized. And still, an implicit "best practice" model does seem to exist, against which national cases are frequently assessed, being portrayed as "good" or "bad" for the deployment of renewables in view of, respectively, convergences and divergences from the model. In this paper, we attempt to systematize what are frequently considered the best policies and institutions for renewable electricity. We also seek to portray the prevailing model as a sector-specific description of the policies and institutions present in liberal market economies. Subsequently, we explore the case of China, arguably not a liberal market economy, where policies and institutions coincide with "best practice" only partially and imperfectly, even following enactment of the nation's Renewable Energy Law (REL) in 2006.
\end{abstract}

Keywords: Renewable energy, Best practice, Policies, Institutions, China.

\section{Introduction and methodology ${ }^{1}$}

There is an extensive literature describing policies and institutions that foster the deployment of renewable energy. To our knowledge, there has been no academic effort to systematically collect the policy and institutional prescriptions posited in diverse sources as "best practice"; such is our current intent. Furthermore, given the diversity of national economic systems, even within market economies, we aim to compile those policies and institutions that constitute a "best practice" model in a way that reveals this model as a sector-specific description of a particular kind of capitalism, sometimes termed "liberal market economy" (LME, as in Hall and Soskice, 2001).

Next, we present China as our case study, whose policies and institutions fit the "best practice" model only partially and imperfectly, even following enactment of a Renewable Energy Law (REL) ${ }^{2}$ in 2006. When judged against the model, Chinese particularities appear to be imperfections, or even obstacles to the deployment of renewables. Since the overall Chinese economic system arguably does not fit the definition of an LME, this case study shows: (1) the need for further research in order to determine whether Chinese particularities are indeed imperfections, or simply the sector-specific manifestation of an alternative variety of capitalism; and (2) the need to question the "best practice" model, insofar its prescriptions might be valid only for certain political economies (those of LMEs).

Our analysis combines a review of specialized literature and the business press with semistructured interviews held with relevant actors in policy, business, and research related to renewable energies. Interviews were conducted at: departments of the Government of Spain; Chinese public research centers (Chinese Academy of Social Sciences, Energy Research

\footnotetext{
${ }^{1}$ The author would like to acknowledge the financial support of a Becas Complutense-Del Amo grant, as well as the insights provided by John Zysman and Steven Vogel, and various doctoral students at University of California, Berkeley.

${ }^{2}$ See the REL at: http://www.ccchina.gov.cn/en/NewsInfo.asp?NewsId=5371 (last accessed November 23, 2009).
} 
Institute, and Pekin University); institutions for international cooperation in energy and the environment; and multinational companies operating in China.

\section{Common views on the policies and institutions needed for GCRE}

\subsection{Overcoming economic barriers to GCRE: policies for the creation of markets}

Economic barriers are those high costs and/or insufficient revenues that prevent greater investment in the deployment of renewable technologies. The purpose of policy, according to the guidelines published by relevant international actors (cited below), should therefore be to remove, or compensate for, such obstacles, thus making renewable technologies competitive vis-à-vis traditional alternatives. As we shall see, the economic barriers identified in the specialized literature are basically obstacles that derive from market distortions or failures that, once removed, allow renewable technologies to move towards market competitiveness.

In particular, governments should aim at: (1) "leveling the playing field for renewables" (IEA, 2007:9); and (2) introducing support instruments for an increasingly cost-effective deployment of renewable technologies. Leveling the field entails the elimination of market distortions that favor traditional sources over GCRE: elimination of subsidies to conventional fuels, plus internalization of negative and/or positive externalities. But even if the playing field is leveled, the deployment of GCRE encounters other economic obstacles which "continue to be financially costlier for the investors in renewable power plants than conventional generation” (World Bank, 2008:47). The most cited include: the higher initial cost of installing generating capacity in GCRE; more restricted access to capital; and insufficient demand. Overcoming these obstacles would be achieved by mandated market policies (World Bank, 2008; REN21 ${ }^{4}$ ), financial incentives, and actions to ensure demand.

Regarding mandated market policies, the usual classification establishes that schemes are either quantity-based (basically renewable portfolio standards, RPS, and tender procedures) or price-based (feed-in tariffs, FITs ${ }^{5}$, and feed-in premiums). Meanwhile, financial incentives for deployment would aim to promote investment by lowering the costs of such investment, via financial and fiscal aids (grants, loans and loan guarantees, tax credits, etc.). Finally, and regarding demand for GCRE, the clearest recommendations are to ensure grid access and to institute Power Purchase Agreements (PPAs). Although there has been much debate over instrument effectiveness - especially between price-based and quantity-based mechanisms the latest recommendations (IEA, 2008; World Bank, 2008) underline the importance, not so much of the choice of a particular instrument, but of how an instrument is implemented. In particular: (1) these schemes should be fine-tuned for each renewable technology; (2) remuneration for each technology should be sufficient to ensure profitability - IEA sets minimum levels of remuneration at USD $0.070 / \mathrm{kWh}$ for wind, and at USD $0.080 / \mathrm{kWh}$ for biomass; (3) the schemes should be of long enough duration to recover investment and ensure profitability; (4) any financial support to renewables should be designed to ensure that both investment and efficiency are achieved, in order to "move technologies quickly towards market competitiveness" (IEA, 2008:23); and (5) production-based supports are preferable to supports to investment, or to installed capacity, since they reward the desired outcome.

\footnotetext{
${ }^{3}$ This discussion is mostly based on IEA, 2008; GWEC, 2005; IREC, 2004; WEC, 2004; World Bank, 2008; and author's interviews (mostly Western interviewees, since these agreed upon most of what constitutes "best practice").

${ }^{4}$ See: http://www.ren21.net/RenewablesPolicy/PolicyInstruments/RegulatoryPolicies/tabid/5623/Default.aspx (last viewed November 23, 2010).

${ }^{5}$ We understand feed-in tariffs as tariffs that are fixed and equal for any generating company.
} 


\subsection{Overcoming non-economic barriers: developing market-friendly institutions}

Guidelines on how to promote the use of renewables also focus on the need to eliminate noneconomic barriers, which some studies identify as particularly damaging to the development of renewables. Non-economic barriers, at the risk of simplification, consist of features of the institutional framework that prevent greater investment in an increasingly cost-effective deployment of renewable technologies. The purpose of policy, therefore, should be to remove institutional barriers that impede the good functioning of markets.

In systematizing the diverse lessons in this arena, we find that: (1) Regarding governmentrelated institutions, it is proposed that "good governance" prevails by way of general legal security, a capable bureaucracy, and predictable regulations for renewables; and (2) regarding corporate-related institutions, prescriptions include low barriers of entry and competition, as well as a technology-friendly corporate structure. It is proposed that State institutions should first tend towards the development of an overall (not only in energy) regulatory framework that is conducive to market transactions. WEC (2004) refers to the non-observance of property rights as a barrier to renewables; and IREC (2004) identifies as detrimental the absence of "transparent and enforced (...) anti-corruption policies and regulations" (IREC, 2004:7). Second, there are calls for a capable, coordinated bureaucracy; even for "joint policy-making and priority setting between energy ministries and rural development, health, education, water, environmental, and other ministries" (IREC, 2004:11). A capable bureaucracy also entails well-trained officials, and fewer administrative hurdles. Third, regulations around renewables should have specific institutional features: goals should be concrete, formally specified, and binding; policies should be long-term and stable, follow preestablished rules, and be simple and transparent. In sum, rules should be predictable: policy effectiveness for deployment "is more affected by the perceived investment risk on renewables projects than on their potential profits and/or costs” (IEA, 2007:11).

Regarding corporate structure, the "best practice" lessons proposed by the literature relate closely to electricity sector reforms. First, production and transmission should be unbundled in order to avoid oligopolies and achieve wholesale competition. Sometimes implicit in the pro-competition rationale, and clearly stated by most Western interviewees, is the need for room for foreign participation, as this could bring about technology and skill upgrades.

\subsection{The "best practice" model as a sector-specific description of an LME}

Here we show how the "best practice" model fits into a broader set of policies and institutions present in an LME. Beginning with policies to overcome economic barriers, the very goal of fostering (private) investment through market-incentives presumes the existence of an LME, where investors are atomized companies making decisions in view of costs and revenues. Note that both major sets of prescribed policies restrict a government's role to perfecting the functioning of markets: leveling the playing field explicitly entails the need to eliminate market distortions and compensate for market failures; and support mechanisms are not meant to be part of industrial policy, but should compensate for economic disadvantages of GCRE vis-à-vis fossil fuels arising from market distortions. Regarding institutions to overcome noneconomic barriers, the goal is an institutional environment that motivates (private) investment. The prescribed institutions basically reflect those of an LME: the role of government is to set and enforce formal and predictable "rules of the game", so that corporations may freely "play" in the market with no major uncertainties and/or discrimination. Thus do prescriptions include legal security, a capable bureaucracy, and predictable regulations, plus low barriers of entry to both domestic and foreign participation. 
The perfecting of markets through arm's length policies and the setting of formal, predictable regulations both fit well into the standard role of a State within an LME. In such a system the State plays an arm's length role while setting competition requirements that prevent coordination between companies. Also, corporate competition in an LME entails that technology transfers occur through market mechanisms, such as hiring or joint ventures (Hall and Soskice, 2001). In similar fashion, the "best practice" model calls for competition or foreign participation as a source of innovation or technology transfer (assuming that these will not be coordinated). Also, LMEs include financial systems with short-term horizons, like those in the "best practice" model (a financial system delinked from the State and nonfinancial corporations, and unwilling to take long-term risks).

\section{Chinese policies and institutions for $\mathrm{GCRE}^{6}$ : divergences from "best practice"}

\subsection{Policies for the creation of markets?}

As for leveling the playing field for renewables vis-à-vis traditional technologies, Cherni and Kentish (2007) describe how the usual market distortions favoring traditional technologies apply to China. The fact that the average tariff paid to coal-fired power generators is at 0.050 $\mathrm{USD} / \mathrm{kWh}^{8}$ somehow reflects the low cost of producing electricity with coal (for comparison, see below for tariffs paid for renewable sources). A revamped tax on coal is being discussed, but the uncertainties around such tax reform are still many ${ }^{9}$. However, China does implement all the aforementioned support-to-deployment instruments: mandated market policies, financial incentives, and support for demand. But as we shall detail, imperfections in implementation (with respect to "best practice”) are significant.

Within quantity-based mandated market policies, China has implemented a renewable electricity standard: all generating companies with installed capacity above 5MW are required to have an installed capacity of renewable energy of at least 3\% of total by 2010 . Note that this obligation refers not to actual power fed into the grid, but merely installed capacity, which, as some interviewees indicated, results in around $30 \%$ of the installed capacity for renewable electricity remaining dormant. Another quantity-based system for GCRE is a tendering system, which prevailed in the case of on-shore wind between 2003 and 2009 and has recently begun to operate for solar. During this period, five national tenders for wind concessions were carried out by the National Development and Reform Commission (NDRC). Winning prices fell between 0.055 and $0.080 \mathrm{USD} / \mathrm{kWh}$; and concessions were for 25 years, but the fixed tariff was guaranteed for the first 30,000 full load hours of operation (GWEC, 2005). Because low remuneration levels and the short duration of fixed tariffs proved insufficient for profitability (Lema and Ruby, 2007; author's interviews), foreign investors were barred from winning these tenders. Remuneration was either below or scarcely above what IEA (2008) identifies as a threshold for deployment of wind power $(0.070$ $\mathrm{USD} / \mathrm{kWh}$ ), and even below the price set for wind in China before the tender system (Lema and Ruby, 2007); also below what some studies have cited as the threshold for profitability (0.082-0.102 USD/kWh, according to Li et al., 2006). Moreover, the 30,000-hour duration of the tariff corresponds to about half of a wind park's life (author's interviews). Finally, the winning of a concession does not necessarily imply that the project will generate and feed

\footnotetext{
${ }^{6}$ Many particular policies and institutions will refer only to onshore wind power, given the lag in regulation for other renewable electricity sources, as well as their still-marginal presence in the Chinese installed capacity mix.

${ }^{7}$ Here we use "author's interviews" as a reference to interviewees, be they Western or Chinese, as long as there was a major coincidence in opinions. Otherwise we make disagreements explicit.

${ }_{9}^{8}$ All data will be provided in USD. Conversions are made at an exchange rate of 6.8 RMB per 1 USD (December 2009).

9 Author's interviews and press articles: http://uk.reuters.com/article/idUKTOE62O02R20100325; http://www.eeo.com.cn/ens/Politics/2010/03/29/166354.shtml (last accessed November 23, 2010).
} 
electricity into the grid (REN21, 2009). Apart from national tenders, all wind projects below $50 \mathrm{MW}$ are to be approved at the provincial level ${ }^{10}$, with specific licensing criteria set locally. According to REN21 (2009), tariffs set for provincial development projects have been between 0.075 and $0.099 \mathrm{USD} / \mathrm{kWh}$, close to what IEA (2008) considers a minimum for deployment and below the estimated threshold for profitability (Li et al., 2006).

Regarding price-based mandated market policies, there is a FIT for biomass, set at the price of coal plus $0.036 \mathrm{USD} / \mathrm{kWh}$ for 15 years (RELaw Assist, 2007); and a FIT for wind was established in July 2009, ranging from $0.075 \mathrm{USD} / \mathrm{kWh}$ to $0.089 \mathrm{USD} / \mathrm{kWh}$. There are expectations that a FIT for solar will follow, to be set between 0.160 and $0.220 \mathrm{USD} / \mathrm{kWh}^{11}$. Given an average coal price of $0.050 \mathrm{USD} / \mathrm{kWh}$, the premium set for biomass raises its FIT to an average of $0.086 \mathrm{USD} / \mathrm{kWh}$, scarcely above what IEA (2008) considers the minimum tariff for policy effectiveness. The FIT for wind also falls very close to the IEA's minimum tariff ${ }^{12}$. Furthermore, although the FIT does set prices slightly above most tariffs resulting from national concessions, it departs little from the average remuneration of independent projects negotiated locally. As with tendering or the independent project systems, the fixed tariffs for wind apply to 30,000 hours of operation, or about half the life of a park. Finally, provisions for the reduction of tariffs over time have been thus far specified only for biomass.

As for financial incentives, we find in China both financial support and fiscal aids. A very recent example of financial support is that solar PV generation projects above 500MW have been eligible, since July 2009, for the enhanced “Golden Sun” project, which includes a 50\% subsidy for all investment ${ }^{13}$. The REL itself, in Article 25, dictates that "financial institutions may offer preferential loan with financial interest subsidy" to projects in renewables. On the fiscal side, there are tax reductions, the most relevant being the $50 \%$ cut in the VAT tax rate for electricity generated by wind (Lema and Ruby, 2007). Article 26 of the REL also includes tax benefits to renewables. In any case, financial support is frequently given to the manufacturing and development of installed capacity, but with scarce incentives to production, efficient use of resources, or quality improvements and cost reductions (Cherni and Kentish, 2007). Finally, China implements certain demand-enhancing schemes. Transmission companies are obliged to provide each facility with connection to the grid, at the connection point closest to the generator; and, under PPAs, they are obliged to purchase all renewable electricity. Nevertheless, grid companies may prove reluctant to comply with rules: grid companies suffer losses from the purchase of renewable power at fixed tariffs (Cherni and Kentish, 2007). Also, even when generators are provided with connection points, these may be too far from the point of generation ${ }^{14}$. Finally, the grid simply lacks the technical requirements for connecting increasing volumes of renewable electricity (author's interviews). In 2008, as a result of difficulties in connection, and coupled with the fact that the RPS applies to installed capacity and not dispatched power, a significant portion of installed wind capacity remains unconnected to the grid (author’s interviews).

\footnotetext{
10 See China's “Administrative Provisions for Renewable Energy Power Generation” (http://www.martinot.info/China RE Law Guidelines 2 NonAuth.pdf; last accessed November 23, 20010).

11 Press article: http://www.renewableenergyworld.com/rea/news/article/2009/08/ldk-solar-signs-500-mw-pv-project-deal (last accessed November 23, 2010).

${ }^{12}$ IEA (2008) notes that even remunerations well above the minimum might not be effective, if not coupled with the removal of non-economic barriers.

13 Press article: http://solarglobalgreen.com/pg/blog/justin/read/1278/china-golden-sun-project-aims-to-speed-constructionof-solar-farms (last accessed April 28, 2010).

14 China's "Administrative Provisions for Renewable Energy Power Generation” (http://www.martinot.info/China_RE_Law_Guidelines_2_NonAuth.pdf; last accessed November 23, 2010) indicates that "the connection system should be built by the power grid enterprises at their own costs", which according to business interviewees does not imply that this is the case over the entire length of the line.
} 


\subsection{Market-friendly institutions for renewables?}

Concerning institutions related to the State, and general legal security, empirical studies, together with our own interviews, show that foreign companies are discouraged by general regulatory uncertainty in China. As for the capability of the bureaucracy to design, implement, and enforce goals and instruments for the promotion of renewables, coordination has increased since the centralization of energy regulation into new public entities (Lema and Ruby, 2007), such as the National Energy Administration (NEA) or the State Electricity Regulatory Commission (SERC). But a multiplicity of stakeholders continues to prevail, posing at least three problems. First, it brings uncertainty to the degree that the de iure or de facto responsibilities of each government organism are unclear ${ }^{15}$. Second, even under the umbrella of Beijing's determination, fragmentation assists the designs of public players disinterested in the development of renewable electricity. For example, Ma and He (2008) explain how Chinese local officials have been historically evaluated according to economic growth, de-prioritizing compliance with environmental regulations. Third, in relation to the multiplicity of stakeholders, there exists in China a multiplication of bureaucratic procedures. As to the quality of policies around renewables, we find that the Chinese government does indeed have specific targets for renewable electricity, as demanded by the "best practice" literature (see for instance NDRC's National Medium- and Long-Term Development Plan for Renewable Energy in China, 2006-2020). Nevertheless, according to Ma and He (2008), those targets are weak insofar as they are not compulsory. Also, China seems not to rank particularly high regarding predictability of policy (resulting mostly from regulation being stable, rules-based, and transparent). For instance, when it comes to clarity and transparency of rules, we see that REL includes very few regulatory details; and other renewable energy legislation in China also lacks specificity (Cherni and Kentish, 2007; IEA, 2007; author's interviews). In particular, there are critiques to the uncertainties around tariffs, connectivity and PPAs (negotiated case-by-case), grid upgrades, and enforcement measures.

We now turn to the corporate structure for renewable electricity. Electrical sector reform included the separation between government and business operations, as well as the unbundling of generation and transmission. Also, an independent regulatory and supervisory agency (the SERC) was established. In any case, reforms in the sector are widely perceived as unfinished, mostly in that free entry and competition are restricted, both in terms of transmission/distribution and generation. Regarding transmission, the State Grid and the Southern State Grid are essentially monopolies, as well as monopsonies, in their respective regions. Also, regulations regarding connection and PPAs are not rigorously enforced, probably because of the limited regulatory capacity of SERC vs. NDRC, and SERC's limited authority over the transmission companies, given the administrative ranks of SOE managers, which parallel those of the government officials at SERC.

In the area of generation, public and private companies are allowed to compete with the "big five" state corporations that resulted from the 2002 unbundling of the State Power Corporation (SPC). But competition is hindered by industry concentration, public ownership and control, and barriers to foreign competition. The latter not only restrict overall competition but also limit the technology and know-how utilized in development and generation. The five big holding companies own nearly $40 \%$ of total generation assets ${ }^{16}$ and produce about half of China's electricity ${ }^{17}$. Much of the remaining assets belong to other

\footnotetext{
${ }^{15}$ See Cherni and Kentish, 2007; Lema and Ruby, 2007; Ma and He, 2008, about the limited authority of SERC vs. NDRC.

${ }^{16}$ Information on asset ownership is as of 2006, and according to Ma and He (2008).

17 Information on production is from the Energy Information Administration of the United States, at http://www.eia.doe.gov/cabs/China/Electricity.html (last accessed November 23, 2010).
} 
companies administered by the central government (10\%) or by local governments (45\%). The "big five" power companies, which traditionally generate electricity with coal, also dominate the renewable power sector. For instance, under the national tender system for wind development, all winners but one have been "big five" subsidiaries (Lema and Ruby, 2007). And seven wind mega-projects planned for construction will be led by China's "big five"18. Moreover, the "big five" are SOEs, and since most other generation assets are controlled by central or local governments, any semblance of market-like competition is hindered further. At the same time, foreign competition in development and generation remains marginal: foreign companies (including joint ventures) produce about $6 \%$ of total electricity in China; and out of the $12 \mathrm{GW}$ installed in wind in 2008, about 95\% belonged to Chinese capital, with most of the remaining $5 \%$ belonging to joint-ventures, and only a marginal share being wholly foreign-owned (author's interviews). The scant presence of foreign developers and generators might be explained by policies already reviewed, which deter foreign investment (author's interviews; RELaw Assist, 2007): (1) the fact that foreign companies could not win concessions through national tendering; (2) low remuneration and short duration for all incentive schemes; and (3) the fact that foreign projects are allowed a debt-financing percentage below the $80 \%$ permitted for domestic projects. Other policies and institutions also reviewed could conceivably deter the entry of any company, but foreign competitors especially: grid access and PPAs that are time-consuming and difficult to negotiate; the general departure of the Chinese legal and contractual framework from Rule of Law principles; administrative hurdles in licensing procedures; institutional weaknesses of the policies for renewables; etc. (Cherni and Kentish, 2007; author’s interviews).

In manufacturing, both industry concentration and the market share of Chinese companies are lower than in power generation. In wind, prior to 2004 there were fewer than five manufacturers of wind-power components. By the end of 2008, wind turbine manufacturers numbered 70 (REN21, 2009). Nevertheless, the three biggest manufacturers dominate, with over half the market ${ }^{19}$. Among those 70 companies making turbines in China, more than 50 are Chinese-owned, eight are joint ventures, and nine are foreign-owned. But the presence of foreign capital in manufacturing has decreased over time: in 2004 the domestic market share for wind turbines was 18\% (GWEC, 2005); the 2008 share for domestic and joint-venture companies was 75\% (REN21, 2009). And in view of certain recent government incentives, it is likely that Chinese companies will continue to increase their market share. For instance, all majority Chinese-owned domestic manufacturers will be awarded up to $\$ 88$ per $\mathrm{kW}$ for their first 50 wind turbines certified and connected to the grid; also, Chinese companies will apparently benefit most from the aforementioned mega-wind farms project $^{20}$. Foreign production of equipment faces some difficulties. Frequently mentioned policies include the 70\%-local-content standard for wind turbines, and the turbines' import duties structure: in 2000 , a $12 \%$ tariff for turbines (3\% for components) was re-introduced. Also, compared to domestic companies, foreign manufacturers face restrictions (some related to policies and institutions described). Examples of discriminatory policies include: the tendering system for wind, which favors turbine price over quality; subsidies for Chinese companies only; and the very recent "buy Chinese" policy wherein projects financed by the economic stimulus package must seek government permission before buying foreign goods and services.

\footnotetext{
${ }^{18}$ Press article: http://www.chinadaily.com.cn/cndy/2009-07/07/content_8385497.htm (last accessed December 10, 2009).

${ }^{19}$ Press article: http://rightsite.asia/en/article/tapping-chinas-wind-turbine-market (last accessed April 26, 2010).

${ }^{20}$ Press article: http://english.peopledaily.com.cn/90001/90778/90857/90860/6694805.html (last accessed April 26, 2010).
} 


\section{Conclusions}

A consensus seems to have emerged, among Western organisms and practitioners, around which policies and institutions are best for GCRE. We find that the "best practice" model basically amounts to a sector-specific description of an LME: policies should consist in regulations that facilitate private investment via the perfection of market mechanisms; and institutions should be market-friendly, also to facilitate investment. In China, arguably not an LME, we have encountered policies and institutions for GCRE that have moved toward the described prescriptions, but gradually and only partially. Although the accuracy of the details presented in this paper may suffer from the rapid pace at which Chinese regulations evolve, general imperfections here mentioned will likely prevail in the medium term.

As stated, when measured against the "best practice” model, China's particularities appear to be obstacles to the deployment of renewable technologies. But, seen in a wider perspective that of China not fitting into the definition of an LME - further research would be necessary to determine whether Chinese particularities are indeed imperfections, or simply the sectorspecific manifestation of an alternative (non-LME) variety of capitalism. Moreover, the fact that China has proven quite successful in GCRE should lead us to question the "best practice" model, insofar its prescriptions might be valid only for certain political economies.

\section{References}

[1] P. Hall and D. Soskice, An Introduction to Varieties of Capitalism, in P. Hall and D. Soskice, Varieties of Capitalism, Oxford University Press, 2001.

[2] IEA, Global Best Practice in Renewable Energy Policy Making Expert Meeting, Workshop Proceedings, IEA, 2007.

[3] IEA, Deploying Renewables. Principles for Effective Policies, IEA, 2008.

[4] GWEC, Wind Force 12. A Blueprint to Achieve 12\% of the World's Electricity from Wind Power by 2020, Report, GWEC and Greenpeace, 2005.

[5] IREC, Policy Recommendations for Renewable Energies, document produced at the International Renewable Energy Conference, 2004.

[6] World Bank, REToolkit: A Resource for Renewable Energy Development, Issues Note of the REToolkit, World Bank, 2008.

[7] WEC, Renewable Energy Projects Handbook, WEC, 2004.

[8] J.A. Cherni and J. Kentish, Renewable Energy Policy and Electricity Market Reforms in China, Energy Policy, 35, 2007, 3616-3629.

[9] A. Lema and K. Ruby, Between Fragmented Authoritarianism and Policy Coordination: Creating Chinese Market for Wind Energy, Energy Policy, 35, 2007, 3879-3890.

[10] J. Li, J. Shi, H. Xie, Y. Song and P. Shi, A Study on the Pricing Policy of Wind Power in China, Chinese Renewable Energy Industries Association and GWEC, 2006.

[11]REN21, Background Paper: Chinese Renewables Status Report, Background Paper, Renewable Energy Policy Network for the 21st Century, 2009.

[12]RELaw Assist, Renewable Energy Law in China. Issues Paper, Australia-China Bilateral Partnership on Climate Change and REEEP, 2007.

[13]C. Ma and L. He, From State Monopoly to Renewable Portfolio: Restructuring China's Electric Utility, Energy Policy, 36, 2008, 1697-1711. 